\title{
Force Field Based MM2 Molecule-Surface Binding Energies for Graphite and Graphene
}

\author{
Jae H. Son, Thomas R. Rybolt ${ }^{*}$ \\ Department of Chemistry, University of Tennessee at Chattanooga, Chattanooga, USA \\ Email: Tom-Rybolt@utc.edu
}

Received November 11, 2012; revised December 12, 2012; accepted January 11, 2013

\begin{abstract}
The gas phase adsorption of 118 organic molecules on graphite and graphene was studied by calculating their molecule-surface binding energies, Ecal*, using molecular mechanics MM2 parameters. Due to the general lack of reported experimental binding energy values for organic molecules with graphene, $\mathrm{E}^{*}$ (graphene), it was considered desirable to have a simple but effective method to estimate these values. Calculated binding energy values using a three-layer model, Ecal*(3), were compared and correlated to published experimental values for graphitic surfaces, E*(graphite). Published values of experimental binding energies for graphite, $\mathrm{E}^{*}$ (graphite), were available from gas-solid chromatogramphy in the Henry's Law region over a range of temperature. Calculated binding energy values using a one-layer model, Ecal*(1), were compared to the three-layer Ecal*(3) values and found to consistently be $93.5 \%$ as large. This relation along with an $\mathrm{E}^{*}$ (graphite) and Ecal*(3) correlation was used to develop a means to estimate molecule-graphene binding energies. Using this approach we report estimated values of 118 molecule-graphene binding energy values.
\end{abstract}

Keywords: Molecule-Graphene Interaction; Molecule-Graphite Interaction; Molecular Mechanics; Adsorption Energy; Binding Energy on Graphene; Binding Energy on Graphite

\section{Introduction}

Graphene is a now well-known single layer of carbons arranged in a hexagonal configuration. Multiple layers of graphene stacked upon each other and held together by van der Waal forces form graphite. Graphene is of great interest because of its many unique properties [1,2]. Graphene is transparent, light, and an excellent conductor of electricity and heat. Its transparency and electric conductivity are desirable properties for touch screen electronic devices. Graphene's thermal and electrical conductivity outperform copper. At room temperature, copper has a thermal conductivity of $401 \mathrm{Wm}^{-1} \cdot \mathrm{K}^{-1}$ while graphene's is $5000 \mathrm{Wm}^{-1} \cdot \mathrm{K}^{-1}$ [3]. The electrical conductivity of copper is $0.60 \times 10^{6} \Omega^{-1} \cdot \mathrm{cm}^{-1}$ and graphene's is $0.96 \times$ $10^{6} \Omega^{-1} \cdot \mathrm{cm}^{-1}$ [3]. The breaking strength of graphene is approximately $42 \mathrm{~N} / \mathrm{m}$ and an equivalent thickness, steel has a value of $0.40 \mathrm{~N} / \mathrm{m}$ [3]. In addition to these striking graphene properties, one promising application of this unique two-dimensional material is as a molecular sensor.

Graphene-based devices have been considered for various electronic and optoelectronic devices as well as gas sensors and biosensors [4]. A single layer of graphene, bilayer of graphene, few-layers of graphene, or

${ }^{*}$ Corresponding author. modified graphene surface can act as a sensor when a molecule adsorbs on the surface and changes the graphene's electric conductivity or other measureable property. The change in conductivity or other property can then be correlated with amount of molecules adsorbed [5]. For example, the electrical conductivity of a graphene fabricated device was observed to increase linearly with an increase of carbon dioxide in the 10 to $100 \mathrm{ppm}$ range [6].

In order to exploit the potential applications of graphene as gas sensors, the adsorption of a series of small gas molecules on pristine graphene and Si-doped graphene have been investigated by ab initio calculations [7]. Their theoretical results indicated that the electronic properties are sensitive to oxygen and nitrogen dioxide adsorption, but not as much modified by the adsorption of carbon monoxide and water [7]. The adsorption of inorganic molecules including water, ammonia, carbon monoxide, nitrogen dioxide, and nitrogen oxide on a graphene substrate were considered using first-principles calculations [8]. Graphene surfaces and variously modified graphene surfaces have been used to develop gas sensor devices and successfully have been used to detect ammonia [9], sulfur dioxide [10], nitrogen dioxide [11], nitrogen dioxide and ammonia [12], carbon dioxide [6], acetone [13], hydrogen sulfide [14], and hydrogen [15, 
16]. A variety of surface modifications have been explored and their detection effects examined [14-20].

Adsorption can be studied theoretically by calculating the adsorption interaction energy (binding energy) of a molecule on the surface. A molecule with higher binding energy should have greater adsorption on the graphene surface. For example, given the same amounts of two different molecules in the gas phase (atmosphere surrounding the graphene sensor surface, for example), the ratio of the amounts of those two molecules physically adsorbed on the surface would be different depending on the relative binding energy. The molecule with the stronger binding energy would be expected to be favored in surface physisorption. Therefore, the study of binding energy is important for developing sensors and correlating sensor responses to amounts physically adsorbed and further correlating these amounts to the actual concentrations in a complex mixed molecule environment around the sensor.

It would be useful to be able to predict single layer graphene binding energies for a variety of organic molecules. There is a lack of gas phase experimental binding energies for organic molecules on graphene. However, there have been many experimental studies relating to molecule adsorption on graphite. Using this moleculegraphite binding energy data, our approach is to study the relationship of calculated and experimental graphite adsorption energies and also of calculated graphite and calculated graphene binding energies. Assuming suitable relations are found then it should be possible to calculate molecule-surface binding energies on graphene or graphite and then predict experimental binding energies of molecules on graphene.

Previous studies showed that MM2 molecular mechanics parameters for atom-carbon van der Waals (vdW) interactions are suitable to effectively predict moleculecarbon surface binding energies [21-25]. In these prior studies of gas-solid interactions, the standard augmented MM2 parameters developed by Allinger [26,27] were used to estimate the binding energies of organic molecules interacting with various model carbon surfaces [2125]. The adsorption of neutral molecules on a carbon surface is dominated by dispersive van der Waals (vdW) forces. In previous studies [21-25] molecule-surface steric energy differences for an adsorbate molecule adjacent to or far from a model adsorbent surface were used to estimate the energy due to adsorption, the binding energy. Although force field calculations do not reference electronic behavior, they have been widely used for determining minimum energies and optimized molecular geometries [28].

\section{Experimental Data}

A review of the literature revealed a lack of experimental organic molecule-graphene interaction energies. However, a significant number of organic molecule-graphite interaction energies have been reported. These experiments typically utilized either thermal programmed desorption (TPD) or gas-solid chromatography (GSC). TPD experiments usually give information about multilayer or monolayer desorption and so molecule-molecule interactions cannot be ignored [21]. However, many GSC determinations involved finding the low coverage Henry's constants and so reflect the interaction of isolated molecules with the carbon surface.

Sample gas corrected retention times can be converted to a Henry's law adsorption constant $\left(\mathrm{K}_{\mathrm{H}}\right)$. In various published studies these Henry law constants were obtained over a range of temperature values [29-42]. A plot of the natural logarithm of $\mathrm{K}_{\mathrm{H}}$ versus the reciprocal of the temperature ( $\mathrm{d} \ln \mathrm{K}_{\mathrm{H}} / \mathrm{d} / \mathrm{T}$ ) gives a plot whose slope is $\mathrm{E}^{*} / \mathrm{R}$ where $\mathrm{E}^{*}$ is the molecule-surface binding energy or adsorption interaction energy and $\mathrm{R}$ is the gas constant. If given as $\mathrm{R}=0.001986 \mathrm{kcal} \cdot \mathrm{K}^{-1} \cdot \mathrm{mol}^{-1}$ then the slope times $\mathrm{R}$ gives the $\mathrm{E}^{*}$ value in $\mathrm{kcal} / \mathrm{mol}$. As $\mathrm{E}^{*}$ increases then it indicates stronger molecule surface interactions.

Published Studies using Graphitized Thermal Carbon Black (GTCB) were selected as suitable graphitic adsorbents. A total of 118 different organic molecules with a variety of structures and functionality determined from GSC on suitable graphitic surfaces were identified and are reported in Table 1. Table 1 gives the assigned molecule number, molecule name, chemical formula, reference source for value, experimental value $E^{*}$, and the organic group to which the molecule is assigned. Experimental binding energy data are reported in various units but were converted to $\mathrm{kcal} / \mathrm{mol}$ for all comparisons. The experimental binding energies or physisorption interaction energies are commonly reported in $\mathrm{eV}, \mathrm{meV}, \mathrm{kJ} / \mathrm{mol}$, and Kelvin. The conversion factors used were based on the relations $1 \mathrm{kcal} / \mathrm{mol}=4.336411 \times 10^{-2} \mathrm{eV}=43.36411$ $\mathrm{meV}=4.184 \mathrm{~kJ} / \mathrm{mol}=503.217 \mathrm{~K}$.

\section{Theory}

The energy of a molecule calculated from molecular mechanics, $\mathrm{E}_{\mathrm{MM}}$, (augmented MM2 parameters were used in this work) is a sum of covalent and noncovalent energies. The MM2 covalent energy contributions include stretch, stretch-bend, angle, dihedral, improper torsion; and the noncovalent energy contributions include electrostatics, hydrogen-bonding, and van der Waals. The van der Waals interaction energy, $E_{v d W}$, is a parameter that contributes to the noncovalent bond energy, and the Van der Waals radius of atoms dominates the moleculegraphite and molecule-graphene interactions. If two nonbonded atoms are pushed too close together, they will strongly repel from one other. If they are at a suitable intermediate range, they will experience a mutual attrac- 
Table 1. Assigned molecule number, molecule name, chemical formula, reference source for value, experimental value $E^{*}$, and the organic group to which the molecule is assigned.

\begin{tabular}{|c|c|c|c|c|c|}
\hline Number & Name & Formula & Ref & $\mathrm{E}^{*}$ (Graphite) $\mathrm{kcal} / \mathrm{mol}$ & Group \\
\hline 1 & butyl aldehyde & $\mathrm{C}_{4} \mathrm{H}_{8} \mathrm{O}$ & 29 & 7.4 & aldehyde \\
\hline 2 & capron aldehyde & $\mathrm{C}_{6} \mathrm{H}_{12} \mathrm{O}$ & 29 & 10.3 & aldehyde \\
\hline 3 & capryl aldehyde & $\mathrm{C}_{8} \mathrm{H}_{16} \mathrm{O}$ & 29 & 13.4 & aldehyde \\
\hline 4 & croton aldehyde & $\mathrm{C}_{4} \mathrm{H}_{6} \mathrm{O}$ & 29 & 8.7 & aldehyde \\
\hline 5 & isobutyl aldehyde & $\mathrm{C}_{4} \mathrm{H}_{8} \mathrm{O}$ & 29 & 7.2 & aldehyde \\
\hline 6 & isovaler aldehyde & $\mathrm{C}_{5} \mathrm{H}_{10} \mathrm{O}$ & 29 & 8.7 & aldehyde \\
\hline 7 & pelargon aldehyde & $\mathrm{C}_{9} \mathrm{H}_{19} \mathrm{O}$ & 29 & 14.1 & aldehyde \\
\hline 8 & propyl aldehyde & $\mathrm{C}_{3} \mathrm{H}_{6} \mathrm{O}$ & 29 & 6.7 & aldehyde \\
\hline 9 & valer aldehyde & $\mathrm{C}_{5} \mathrm{H}_{10} \mathrm{O}$ & 29 & 8.8 & aldehyde \\
\hline 10 & ethane & $\mathrm{C}_{2} \mathrm{H}_{6}$ & 30 & 4.3 & alkane \\
\hline 11 & n-butane & $\mathrm{C}_{4} \mathrm{H}_{10}$ & 30 & 6.8 & alkane \\
\hline 12 & n-decane & $\mathrm{C}_{10} \mathrm{H}_{22}$ & 31 & 16.1 & alkane \\
\hline 13 & n-heptane & $\mathrm{C}_{7} \mathrm{H}_{16}$ & 31 & 11.7 & alkane \\
\hline 14 & n-hexane & $\mathrm{C}_{6} \mathrm{H}_{14}$ & 31 & 10.3 & alkane \\
\hline 15 & n-nonane & $\mathrm{C}_{9} \mathrm{H}_{20}$ & 31 & 14.6 & alkane \\
\hline 16 & n-octane & $\mathrm{C}_{8} \mathrm{H}_{18}$ & 31 & 13.3 & alkane \\
\hline 17 & n-propane & $\mathrm{C}_{3} \mathrm{H}_{8}$ & 30 & 5.3 & alkane \\
\hline 18 & n-1-butene & $\mathrm{C}_{4} \mathrm{H}_{8}$ & 30 & 6.7 & alkene \\
\hline 19 & n-1-decene & $\mathrm{C}_{10} \mathrm{H}_{20}$ & 31 & 15.3 & alkene \\
\hline 20 & n-1-heptene & $\mathrm{C}_{7} \mathrm{H}_{14}$ & 31 & 11.2 & alkene \\
\hline 21 & n-1-hexene & $\mathrm{C}_{6} \mathrm{H}_{12}$ & 31 & 10.0 & alkene \\
\hline 22 & n-1-nonene & $\mathrm{C}_{9} \mathrm{H}_{18}$ & 31 & 14.2 & alkene \\
\hline 23 & n-1-octene & $\mathrm{C}_{8} \mathrm{H}_{16}$ & 31 & 12.9 & alkene \\
\hline 24 & allyl alcohol & $\mathrm{C}_{3} \mathrm{H}_{6} \mathrm{O}$ & 29 & 6.4 & alkyl alcohol \\
\hline 25 & heptanol-1 & $\mathrm{C}_{7} \mathrm{H}_{16} \mathrm{O}$ & 29 & 12.4 & alkyl alcohol \\
\hline 26 & hexanol-1 & $\mathrm{C}_{6} \mathrm{H}_{14} \mathrm{O}$ & 29 & 10.9 & alkyl alcohol \\
\hline 27 & Isoamyl alcohol & $\mathrm{C}_{5} \mathrm{H}_{12} \mathrm{O}$ & 29 & 8.5 & alkyl alcohol \\
\hline 28 & isobutyl alchol & $\mathrm{C}_{4} \mathrm{H}_{10} \mathrm{O}$ & 29 & 7.5 & alkyl alcohol \\
\hline 29 & isopropyl alcohol & $\mathrm{C}_{3} \mathrm{H}_{6} \mathrm{O}$ & 29 & 6.7 & alkyl alcohol \\
\hline 30 & n-pentanol & $\mathrm{C}_{5} \mathrm{H}_{12} \mathrm{O}$ & 29 & 9.5 & alkyl alcohol \\
\hline 31 & n-butyl alcohol & $\mathrm{C}_{4} \mathrm{H}_{10} \mathrm{O}$ & 29 & 8.3 & alkyl alcohol \\
\hline 32 & propyl alcohol & $\mathrm{C}_{3} \mathrm{H}_{6} \mathrm{O}$ & 29 & 6.8 & alkyl alcohol \\
\hline 33 & secondary amyl alcohol & $\mathrm{C}_{5} \mathrm{H}_{12} \mathrm{O}$ & 29 & 8.6 & alkyl alcohol \\
\hline 34 & secondary butyl alcohol & $\mathrm{C}_{4} \mathrm{H}_{10} \mathrm{O}$ & 29 & 7.6 & alkyl alcohol \\
\hline 35 & tertiary amy alcohol & $\mathrm{C}_{5} \mathrm{H}_{12} \mathrm{O}$ & 29 & 7.8 & alkyl alcohol \\
\hline 36 & tertiary butyl alcohol & $\mathrm{C}_{4} \mathrm{H}_{10} \mathrm{O}$ & 29 & 7.2 & alkyl alcohol \\
\hline 37 & di-n-propylamine & $\mathrm{C}_{10} \mathrm{H}_{19} \mathrm{~N}$ & 32 & 15.8 & alkyl amine \\
\hline 38 & dibutylamine & $\mathrm{C}_{8} \mathrm{H}_{19} \mathrm{~N}$ & 32 & 13.3 & alkyl amine \\
\hline 39 & diisobutylamine & $\mathrm{C}_{8} \mathrm{H}_{19} \mathrm{~N}$ & 32 & 12.2 & alkyl amine \\
\hline
\end{tabular}


Continued

\begin{tabular}{|c|c|c|c|c|c|}
\hline 40 & dipropylamine & $\mathrm{C}_{6} \mathrm{H}_{15} \mathrm{~N}$ & 32 & 10.3 & alkyl amine \\
\hline 41 & tri-n-propylamine & $\mathrm{C}_{15} \mathrm{H}_{33} \mathrm{~N}$ & 32 & 21.3 & alkyl amine \\
\hline 42 & tributylamine & $\mathrm{C}_{12} \mathrm{H}_{27} \mathrm{~N}$ & 32 & 17.3 & alkyl amine \\
\hline 43 & triethylamine & $\mathrm{C}_{6} \mathrm{H}_{15} \mathrm{~N}$ & 32 & 8.7 & alkyl amine \\
\hline 44 & hexyne & $\mathrm{C}_{6} \mathrm{H}_{10}$ & 29 & 8.6 & alkyne \\
\hline 45 & 1-aminoadamantane & $\mathrm{C}_{10} \mathrm{H}_{17} \mathrm{~N}$ & 33 & 10.4 & aromatic amine \\
\hline 46 & 1,3,5-triazine & $\mathrm{C}_{3} \mathrm{H}_{3} \mathrm{~N}_{3}$ & 34 & 8.0 & aromatic amine \\
\hline 47 & 1,8-dimethyl naphthalene & $\mathrm{C}_{12} \mathrm{H}_{12}$ & 35 & 17.4 & aromatic amine \\
\hline 48 & 2-aminoadamantane & $\mathrm{C}_{10} \mathrm{H}_{17} \mathrm{~N}$ & 33 & 10.7 & aromatic amine \\
\hline 49 & 2,3-dimethyl indol & $\mathrm{C}_{10} \mathrm{H}_{11} \mathrm{~N}$ & 32 & 16.9 & aromatic amine \\
\hline 50 & 3-methyl indol & $\mathrm{C}_{9} \mathrm{H}_{9} \mathrm{~N}$ & 32 & 16.0 & aromatic amine \\
\hline 51 & alpha-naphthylamine & $\mathrm{C}_{10} \mathrm{H}_{9} \mathrm{~N}$ & 32 & 17.4 & aromatic amine \\
\hline 52 & alpha-phenyl propionitrile & $\mathrm{C}_{9} \mathrm{H}_{9} \mathrm{~N}$ & 32 & 12.8 & aromatic amine \\
\hline 53 & alpha-phenylethylamine & $\mathrm{C}_{8} \mathrm{H}_{11} \mathrm{~N}$ & 32 & 12.6 & aromatic amine \\
\hline 54 & aniline & $\mathrm{C}_{6} \mathrm{H}_{7} \mathrm{~N}$ & 32 & 11.6 & aromatic amine \\
\hline 55 & Benzonitrile & $\mathrm{C}_{7} \mathrm{H}_{5} \mathrm{~N}$ & 32 & 11.9 & aromatic amine \\
\hline 56 & beta-naphthylamine & $\mathrm{C}_{10} \mathrm{H}_{9} \mathrm{~N}$ & 32 & 17.6 & aromatic amine \\
\hline 57 & diphenylamine & $\mathrm{C}_{12} \mathrm{H}_{11} \mathrm{~N}$ & 32 & 21.1 & aromatic amine \\
\hline 58 & indol & $\mathrm{C}_{8} \mathrm{H}_{7} \mathrm{~N}$ & 32 & 15.0 & aromatic amine \\
\hline 59 & m-toluidine & $\mathrm{C}_{7} \mathrm{H}_{9} \mathrm{~N}$ & 32 & 13.3 & aromatic amine \\
\hline 60 & $\mathrm{~N}$-methylaniline & $\mathrm{C}_{7} \mathrm{H}_{9} \mathrm{~N}$ & 32 & 13.6 & aromatic amine \\
\hline 61 & $\mathrm{~N}, \mathrm{~N}$-diethylaniline & $\mathrm{C}_{10} \mathrm{H}_{15} \mathrm{~N}$ & 32 & 16.5 & aromatic amine \\
\hline 62 & $\mathrm{~N}, \mathrm{~N}$-dimethylaniline & $\mathrm{C}_{8} \mathrm{H}_{11} \mathrm{~N}$ & 32 & 15.3 & aromatic amine \\
\hline 63 & O-toluidine & $\mathrm{C}_{7} \mathrm{H}_{9} \mathrm{~N}$ & 32 & 13.3 & aromatic amine \\
\hline 64 & p-toluidine & $\mathrm{C}_{7} \mathrm{H}_{9} \mathrm{~N}$ & 32 & 13.4 & aromatic amine \\
\hline 65 & Pyrazine & $\mathrm{C}_{4} \mathrm{H}_{4} \mathrm{~N}_{2}$ & 34 & 8.7 & aromatic amine \\
\hline 66 & Pyridine & $\mathrm{C}_{5} \mathrm{H}_{5} \mathrm{~N}$ & 34 & 9.3 & aromatic amine \\
\hline 67 & 1-methyl-naphthalene & $\mathrm{C}_{11} \mathrm{H}_{10}$ & 30 & 15.8 & benzene \\
\hline 68 & 1,2,3,5-tetramethyl & $\mathrm{C}_{10} \mathrm{H}_{14}$ & 36 & 15.8 & benzene \\
\hline 69 & 1,2,4-trimethylbenzene & $\mathrm{C}_{9} \mathrm{H}_{12}$ & 36 & 14.5 & benzene \\
\hline 70 & 1,3,5-trimethylbenzene & $\mathrm{C}_{9} \mathrm{H}_{12}$ & 36 & 14.3 & benzene \\
\hline 71 & 2,3-dimethylnaphthalene & $\mathrm{C}_{12} \mathrm{H}_{12}$ & 35 & 18.2 & benzene \\
\hline 72 & alpha-methyl naphthalene & $\mathrm{C}_{11} \mathrm{H}_{10}$ & 35 & 17.0 & benzene \\
\hline 73 & benzene & $\mathrm{C}_{6} \mathrm{H}_{6}$ & 36 & 8.9 & benzene \\
\hline 74 & beta-methyl naphthalene & $\mathrm{C}_{11} \mathrm{H}_{10}$ & 35 & 17 & benzene \\
\hline 75 & biphenyl acetylene & $\mathrm{C}_{14} \mathrm{H}_{10}$ & 37 & 20.6 & benzene \\
\hline 76 & diphenyl & $\mathrm{C}_{12} \mathrm{H}_{10}$ & 36 & 16.3 & benzene \\
\hline 77 & ethyl benzene & $\mathrm{C}_{8} \mathrm{H}_{10}$ & 36 & 11.2 & benzene \\
\hline 78 & fluorene & $\mathrm{C}_{13} \mathrm{H}_{10}$ & 38 & 19.4 & benzene \\
\hline 79 & hexa-methyl benzene & $\mathrm{C}_{12} \mathrm{H}_{18}$ & 36 & 18.7 & benzene \\
\hline 80 & iso-propyl benzene & $\mathrm{C}_{9} \mathrm{H}_{12}$ & 36 & 11.5 & benzene \\
\hline
\end{tabular}


Continued

\begin{tabular}{|c|c|c|c|c|c|}
\hline 81 & m-xylene & $\mathrm{C}_{8} \mathrm{H}_{10}$ & 36 & 12.6 & benzene \\
\hline 82 & n-pentyl benzene & $\mathrm{C}_{11} \mathrm{H}_{16}$ & 36 & 14.6 & benzene \\
\hline 83 & n-butyl benzene & $\mathrm{C}_{10} \mathrm{H}_{14}$ & 36 & 13.6 & benzene \\
\hline 84 & n-propyl benzene & $\mathrm{C}_{9} \mathrm{H}_{12}$ & 36 & 12.8 & benzene \\
\hline 85 & naphthalene & $\mathrm{C}_{10} \mathrm{H}_{8}$ & 36 & 14.9 & benzene \\
\hline 86 & o-xylene & $\mathrm{C}_{8} \mathrm{H}_{10}$ & 36 & 12.6 & benzene \\
\hline 87 & p-xylene & $\mathrm{C}_{8} \mathrm{H}_{10}$ & 36 & 12.6 & benzene \\
\hline 88 & para-terphenyl & $\mathrm{C}_{18} \mathrm{H}_{14}$ & 39 & 22.7 & benzene \\
\hline 89 & penta-methyl benzene & $\mathrm{C}_{11} \mathrm{H}_{16}$ & 36 & 17.4 & benzene \\
\hline 90 & toluene & $\mathrm{C}_{7} \mathrm{H}_{8}$ & 36 & 10.3 & benzene \\
\hline 91 & 1,3-dichlorobenzene & $\mathrm{C}_{6} \mathrm{H}_{4} \mathrm{Cl}_{2}$ & 40 & 12.4 & chloro aromatic \\
\hline 92 & 1,4-dichlorobenzene & $\mathrm{C}_{6} \mathrm{H}_{4} \mathrm{Cl}_{2}$ & 40 & 12.7 & chloro aromatic \\
\hline 93 & 2-chlorodiphenyl & $\mathrm{C}_{12} \mathrm{H}_{9} \mathrm{Cl}$ & 41 & 15.8 & chloro aromatic \\
\hline 94 & 2,6-dichlorodiphenyl & $\mathrm{C}_{12} \mathrm{H}_{8} \mathrm{Cl}_{2}$ & 41 & 16.2 & chloro aromatic \\
\hline 95 & 2,6,2-trichlorodiphenyl & $\mathrm{C}_{12} \mathrm{H}_{7} \mathrm{Cl}_{3}$ & 41 & 16.2 & chloro aromatic \\
\hline 96 & 2,4,6-trichlorodiphenyl & $\mathrm{C}_{12} \mathrm{H}_{7} \mathrm{Cl}_{3}$ & 41 & 17.7 & chloro aromatic \\
\hline 97 & 4-chlorodiphenyl & $\mathrm{C}_{12} \mathrm{H}_{9} \mathrm{Cl}$ & 41 & 17.5 & chloro aromatic \\
\hline 98 & chlorobenzene & $\mathrm{C}_{6} \mathrm{H}_{5} \mathrm{Cl}$ & 40 & 10.6 & chloro aromatic \\
\hline 99 & cyclohexane & $\mathrm{C}_{6} \mathrm{H}_{12}$ & 36 & 7.0 & cycloalkane \\
\hline 100 & ethyl cyclohexane & $\mathrm{C}_{8} \mathrm{H}_{16}$ & 42 & 10.2 & cycloalkane \\
\hline 101 & isopropyl cyclohexane & $\mathrm{C}_{9} \mathrm{H}_{18}$ & 42 & 11.0 & cycloalkane \\
\hline 102 & methyl cyclohexane & $\mathrm{C}_{7} \mathrm{H}_{14}$ & 42 & 8.5 & cycloalkane \\
\hline 103 & acetone & $\mathrm{C}_{3} \mathrm{H}_{6} \mathrm{O}$ & 29 & 6.4 & ketone \\
\hline 104 & dibutyl acetone & $\mathrm{C}_{9} \mathrm{H}_{18} \mathrm{O}$ & 29 & 14.3 & ketone \\
\hline 105 & dipropyl acetone & $\mathrm{C}_{7} \mathrm{H}_{14} \mathrm{O}$ & 29 & 11.1 & ketone \\
\hline 106 & ethyl-isoamyl-acetone & $\mathrm{C}_{8} \mathrm{H}_{16} \mathrm{O}$ & 29 & 12.1 & ketone \\
\hline 107 & mesityl oxyde & $\mathrm{C}_{6} \mathrm{H}_{10} \mathrm{O}$ & 29 & 11.4 & ketone \\
\hline 108 & methyl-butyl-acetone & $\mathrm{C}_{6} \mathrm{H}_{12} \mathrm{O}$ & 29 & 10.3 & ketone \\
\hline 109 & methyl-ethyl-acetone & $\mathrm{C}_{4} \mathrm{H}_{8} \mathrm{O}$ & 29 & 7.9 & ketone \\
\hline 110 & methyl-heptyl acetone & $\mathrm{C}_{9} \mathrm{H}_{18} \mathrm{O}$ & 29 & 14.9 & ketone \\
\hline 111 & methyl-hexyl acetone & $\mathrm{C}_{8} \mathrm{H}_{16} \mathrm{O}$ & 29 & 13.1 & ketone \\
\hline 112 & methyl-isobutyl-acetone & $\mathrm{C}_{6} \mathrm{H}_{12} \mathrm{O}$ & 29 & 9.9 & ketone \\
\hline 113 & 2-methyl thiophene & $\mathrm{C}_{5} \mathrm{H}_{7} \mathrm{~S}$ & 40 & 10.0 & thiophene \\
\hline 114 & 2-methylthianaphene & $\mathrm{C}_{9} \mathrm{H}_{9} \mathrm{~S}$ & 40 & 15.8 & thiophene \\
\hline 115 & 3-methyl thiophene & $\mathrm{C}_{5} \mathrm{H}_{7} \mathrm{~S}$ & 40 & 10.0 & thiophene \\
\hline 116 & 3-methylthianaphene & $\mathrm{C}_{9} \mathrm{H}_{9} \mathrm{~S}$ & 40 & 15.8 & thiophene \\
\hline 117 & thianaphthene & $\mathrm{C}_{8} \mathrm{H}_{6} \mathrm{~S}$ & 40 & 14.1 & thiophene \\
\hline 118 & thiophene & $\mathrm{C}_{4} \mathrm{H}_{4} \mathrm{~S}$ & 40 & 8.0 & thiophene \\
\hline
\end{tabular}


tive. However, there is no interaction when the atoms are a long distance from each other.

The calculated binding energy, Ecal*, can be determined from

$$
\text { Ecal }^{*}=\mathrm{E}_{\mathrm{ms}}-\left(\mathrm{E}_{\mathrm{s}}+\mathrm{E}_{\mathrm{m}}\right)
$$

where $E_{m}$ is the energy of an isolated gas phase molecule, $E_{s}$ is the energy of the isolated surface adsorbent material, and $E_{m s}$ is the energy of the molecule and solid surface system where the molecule is placed on the surface to represent the adsorbed state [21]. Considering the equation above to represent the final minus the initial state, the molecule has gone from being free in the gas phase to being adsorbed on the surface. The energy of adsorption is a negative energy value but the values are reported here as absolute values and in $\mathrm{kcal} / \mathrm{mol}$ since these units are frequently used in molecular modeling. Desorption energies would be positive values since an input of energy is required. The equation above is equivalent to considering the energy difference, $\Delta \mathrm{E}$, as

$$
\Delta \mathrm{E}=\mathrm{E}_{\text {near }}-\mathrm{E}_{\text {far }}
$$

with respect to the energy of the molecule adsorbed on the surface, $E_{\text {near }}$, and the energy of the separated and non-interacting molecule and surface, $\mathrm{E}_{\mathrm{far}}$. Therefore Ecal $^{*}=\Delta \mathrm{E}$. To distinguish the experimental and calculated binding energies they are indicated as $\mathrm{E}^{*}$ and $\mathrm{Ecal}^{*}$, respectively.

The experimental binding energies on a single layer graphene surface and many layer graphite surface are reported as $\mathrm{E}^{*}$ (graphene) and $\mathrm{E}^{*}$ (graphite), respectively. Molecular modeling values of a one layer graphene and a three layer graphite surface are indicated as Ecal*(1) and Ecal*(3), respectively. In prior work it has been shown that a three graphene layer was adequate to represent molecule-graphite interactions in molecular modeling calculations [21]. More than $90 \%$ of the vdW interaction is due to the first layer, less than $10 \%$ due to the second layer and $1 \%$ or less due to the third layer in the MM2 parameters for molecule carbon surface interactions [21]. Our interest is in predicting $\mathrm{E}^{*}$ (graphene) values for organic molecules. This work considers how $\mathrm{E}^{*}$ (graphene), $\mathrm{E}^{*}$ (graphite), Ecal*(1), and Ecal*(3) are all intercomnected.

The relationship between the experimental E*(graphite) and calculated Ecal*(3) can be expressed as

$$
\mathrm{E} *(\text { graphite })=\alpha \mathrm{Ecal} *(3)
$$

where $\alpha$ is the coefficient or equation multiplied by Ecal*(3) to approximate $E^{*}$ (graphite). This equation assumes either a simple linear relation with a fixed $\alpha$ or an $\alpha$ based on an equation to provide a connection between the experimental and model calculated values and assumes a relation that scales to zero as the values decrease.
Such a relation was observed and various methods used to generate the $\alpha$ term or equation are discussed subsequently.

The relationship between the calculated values for the graphene one-layer and graphite three-layer model surfaces may be expressed as

$$
\operatorname{Ecal} *(1)=\beta \mathrm{Ecal} *(3)
$$

where $\beta$ is the coefficient multiplied by Ecal*(3) to approximate $\mathrm{Ecal}^{*}(1)$. This equation assumes a linear relation between the molecular modeling binding energies calculated for our graphene one layer surface model and our graphite three-layer surface model and a relation that scales to zero as the values decrease. Such a relation was observed between these calculated values and will be discussed.

We further assume that the relationship between the experimental $E^{*}$ (graphene) and calculated Ecal*(1) will be analogous to Equation (3) and thus can be expressed as

$$
\mathrm{E} *(\text { graphene })=\alpha \mathrm{Ecal}^{*}(1) \text {. }
$$

Based on the above equations, predictions of moleculegraphene binding energies can be made by calculating Ecal*(1) and using Equation (5) or instead by calculating

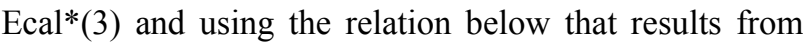
combining Equations (4) and (5) to give

$$
\mathrm{E}^{*}(\text { graphene })=\alpha \beta \mathrm{Ecal}^{*}(3) \text {. }
$$

Such an approach gives a means to reasonable estimate binding energies on graphene provided Equations (3) and (4) are found to be valid.

Prior work on flat, rough, and porous surfaces has indicated that MM2 parameters may be used to calculate molecule-surface binding energies that compare well to experimental values obtained from gas-solid chromatography (GSC) in the Henry's Law region of low coverage over a range of temperatures [22-25]. With a modified model that took into account molecule-molecule nearest neighbor interactions, monolayer coverage binding energies were obtained that compared well to values obtained from thermal program desorption (TPD). For example the published $\mathrm{E}^{*}$ and our calculated Ecal* associated with monolayer desorption from graphite were found to be 0.50 and $0.52,0.72$ and $0.71,1.41$ and 1.47 , and 2.18 and $1.86 \mathrm{eV}$ for benzene, o-dichlorobenzene, coronene, and ovalene, respectively [21].

Previously binding energies for DNA/RNA nucleobases adsorbed on single layer graphene were calculated [43]. These calculations using direct classical MM2 parameters without modification compared well to more sophisticated quantum calculations. The molecular mechanics Ecal* values were observed to be between the values from Moller-Plesset perturbation theory which 
were reported to overestimate and the values from density functional theory (DFT) which were reported to underestimate molecule-surface binding energies [43].

The goal of this work is to develop a simple and effective means to estimate molecule-surface binding energy values for a variety of organic molecules adsorbed on graphene by comparisons to known molecule-graphite binding energy values.

\section{Analysis and Results}

Molecular mechanics MM2 calculations were performed with Scigress computer software (Fujitsu, Version 7.7.0) with the geometry optimized in mechanics using augmented MM2 parameters. The graphene model surface consisted of one layer of 702 benzene rings with no hydrogen atoms. The graphite model surface consisted of three of these layers each containing 702 rings. The layers were oriented in the form of Bernal graphite with the first layer and third layer directly aligned and the second layer offset by half a benzene ring.

To simulate the adsorption of molecules with graphite or graphene, molecules were oriented parallel to the surface and adjusted to maximize the physical interaction of molecules on the surface. The rules used for molecule placement were that first, a carbon from a methyl group of the molecule was placed above the middle of the center benzene ring in the top layer. The carbon was placed in the middle by making it equidistant from 3 alternating carbon atoms in the ring. Second, if the molecule was a cyclo or benzene containing molecules with no attached alkyl groups attached, then some carbon in the ring was selected and centered above the surface six member ring. Third the molecule was further oriented so that the more polarizable atoms were nearest the surface. The molecule was then pushed in closer than an expected optimal separation. With distances between the molecules and the surfaces of approximately $0.23-0.27 \mathrm{~nm}$, the molecules were pushed out to the optimal distance after the molecular mechanics energy optimization calculation.

The 118 molecules listed in Table 1 were modeled and optimized as isolated molecules in the gas phase to calculate $\mathrm{E}_{\mathrm{m}}$, and as described above, the molecules were then placed on a graphite model surface to calculate the $\mathrm{E}_{\mathrm{ms}}$ energy. For each molecule these two values were used along with the $\mathrm{E}_{\mathrm{s}}$ energy for the graphite three-layer model surface and Equation (1) to calculate Ecal*(3). The model-based calculated values of Ecal*(3) for 118 molecules are given in Table 2 where they may be compared to the experimental values found in Table 1. The ratios of $E^{*}$ (Graphite)/Ecal*(3) were found to vary from 0.77 to 1.12 and these values also are given in Table 2 .

A series of different approaches were examined to find the best means of correlation between the $\mathrm{E}^{*}$ (graphite) and Ecal*(3) values. These approaches included (Method I) direct correlation of all data, (Method II) correlations of molecule subsets, (Method III) correlation of rigid and flexible subgroups, and (Method IV) correlation based on consideration of fraction of non-hydrogen atoms that are $\mathrm{sp}^{3}$ carbon atoms.

In Method I values of $E^{*}$ (graphite) vs. Ecal*(3) were plotted and a linear regression through the origin determined. A graph through the origin is desirable so that the $\mathrm{E}^{*}$ (graphite) and Ecal*(3) values scale to zero appropriately. The resultant linear equation (see Figure 1) is

$$
\mathrm{E} *(\text { graphite })=0.9321 \mathrm{Ecal} *(3)
$$

with $\mathrm{R}^{2}=0.8906$ and $\mathrm{n}=118$.

In Method II comparison, the 118 molecules were divided into 11 different functional groups that included aldehyde, alkane, alkene/alkyne, alkyl alcohol, alkyl amine, aromatic amine, benzene derivative, chlorobenzene, cycloalkane, ketone, and thiophene. $E^{*}$ (graphite) data versus Ecal*(3) data, were plotted for each of the 11 groups of molecules. As mentioned previously, for appropriate scaling all linear regressions were required to go through the origin. Table 3 gives the number of data points, the slope, and the $\mathrm{R}^{2}$ values for each group. The data points available within a group varied from a low of 4 molecules in the cycloalkane category to a high of 24 in the benzene derivative category. As shown in Table 3 , the $\mathrm{R}^{2}$ values varied from a low of 0.8726 for cycloalkane (n $=4)$ to a high of 0.9756 for alkene/alkyne $(n=7)$. The slopes varied from a low of 0.8729 for alkane to 1.0312 for chloroaromatic. Recall that for the combined set of all the molecules $(n=118)$ the $R^{2}$ value was 0.8906 . All the subset groups have a higher $\mathrm{R}^{2}$ except for the cycloalkane at 0.8726 .

Method III was based on the observation that the linear regressions of aromatic amine, benzene derivative, chloroaromatic, and thiophene have slopes of 1.0169, 0.9633, 1.0312 , and 0.9936 , respectively. This indicates that the computed interaction energies, Ecal*(3) values that without modification agreed well with the experimental values of $\mathrm{E}^{*}$ (graphite). So if a molecule had a benzene or other flat ring structure such as the thiophene, the molecule was classified as "rigid." Therefore the aromatic amine, benzene derivative, chloroaromatic, and thiophene groups were combined and considered together as the rigid group. When all these data $(n=60)$ are plotted together, the correlating equation is

$$
\mathrm{E} *(\text { graphite })=0.9918 \mathrm{Ecal}^{*}(3)
$$

with $\left(\mathrm{R}^{2}=0.9130\right)$.

As shown in Table 3, the data for the remaining groups of molecules: aldehyde, alkane, alkene/alkyne, alkyl alcohol, alkyl amine cycloalkane, and ketone had slopes that varied from 0.8288 for alkyl amine to 0.9057 
Table 2. Molecule numbers with the calculated binding energy values for graphite Ecal*(3), modified graphite values Ecal*(3)-mod, ratio of experimental to calculated graphite binding energies $E^{*} / E c a l *(3)$, ratio of experimental to modified calculated graphite binding energies $\mathrm{E}^{*} / \mathrm{Ecal} *(3)$-mod, calculated one layer graphene values Ecal*(1), and predicted values for graphene binding energies.

\begin{tabular}{|c|c|c|c|c|c|c|}
\hline Number & Ecal*(3) kcal/mol & Ecal*(3)-mod kcal/mol & $\mathrm{E}^{*} / \mathrm{Ecal}^{*}(3)$ & $\mathrm{E}^{*} / \mathrm{Ecal}^{*}(3)-\bmod$ & Ecal*(1) $\mathrm{kcal} / \mathrm{mol}$ & $\mathrm{E}^{*}$ (graphene)-predict kcal $/ \mathrm{mol}$ \\
\hline 1 & 8.6506 & 7.7828 & 0.86 & 0.95 & 8.1015 & 7.3 \\
\hline 2 & 11.1165 & 9.742 & 0.93 & 1.06 & 10.4058 & 9.1 \\
\hline 3 & 14.9574 & 12.9141 & 0.90 & 1.04 & 13.9463 & 12.0 \\
\hline 4 & 8.2166 & 8.0632 & 1.06 & 1.08 & 7.6482 & 7.5 \\
\hline 5 & 7.3589 & 6.6207 & 0.98 & 1.09 & 7.0007 & 6.3 \\
\hline 6 & 8.8775 & 7.8661 & 0.98 & 1.11 & 8.3008 & 7.4 \\
\hline 7 & 16.5201 & 14.1884 & 0.85 & 0.99 & 15.4480 & 13.3 \\
\hline 8 & 6.8425 & 6.2958 & 0.98 & 1.06 & 6.4034 & 5.9 \\
\hline 9 & 10.3547 & 9.175 & 0.85 & 0.96 & 9.7028 & 8.6 \\
\hline 10 & 4.7612 & 3.8948 & 0.90 & 1.10 & 4.4724 & 3.7 \\
\hline 11 & 8.4293 & 6.8954 & 0.81 & 0.99 & 7.9153 & 6.5 \\
\hline 12 & 19.6667 & 16.0879 & 0.82 & 1.00 & 18.4730 & 18.8 \\
\hline 13 & 14.0388 & 11.4841 & 0.83 & 1.02 & 13.2000 & 10.8 \\
\hline 14 & 12.0938 & 9.8931 & 0.85 & 1.04 & 11.3530 & 10.9 \\
\hline 15 & 17.7549 & 14.524 & 0.82 & 1.01 & 16.6638 & 13.6 \\
\hline 16 & 15.7817 & 12.9099 & 0.84 & 1.03 & 14.8105 & 12.1 \\
\hline 17 & 6.6601 & 5.4481 & 0.80 & 0.97 & 6.2488 & 5.1 \\
\hline 18 & 7.311 & 6.7268 & 0.92 & 1.00 & 6.8623 & 6.3 \\
\hline 19 & 18.2374 & 15.6633 & 0.84 & 0.98 & 16.8021 & 14.5 \\
\hline 20 & 12.5233 & 10.9748 & 0.89 & 1.02 & 11.6826 & 10.2 \\
\hline 21 & 10.7325 & 9.5098 & 0.93 & 1.05 & 10.0684 & 10.3 \\
\hline 22 & 16.2582 & 14.0372 & 0.87 & 1.01 & 15.2171 & 15.2 \\
\hline 23 & 14.4672 & 12.5729 & 0.89 & 1.03 & 13.5386 & 11.8 \\
\hline 24 & 6.9502 & 6.7495 & 0.92 & 0.95 & 6.5403 & 6.4 \\
\hline 25 & 15.1773 & 12.8027 & 0.82 & 0.97 & 14.2459 & 12.0 \\
\hline 26 & 13.4105 & 11.3612 & 0.81 & 0.96 & 12.5882 & 10.7 \\
\hline 27 & 10.2173 & 8.7056 & 0.83 & 0.98 & 9.6006 & 8.2 \\
\hline 28 & 8.2506 & 7.0861 & 0.91 & 1.06 & 7.7106 & 6.6 \\
\hline 29 & 7.163 & 6.2251 & 0.94 & 1.08 & 6.7163 & 5.8 \\
\hline 30 & 11.5711 & 9.8592 & 0.82 & 0.96 & 10.8568 & 9.3 \\
\hline 31 & 9.8345 & 8.4464 & 0.84 & 0.98 & 9.2276 & 7.9 \\
\hline 32 & 7.8316 & 6.8061 & 0.87 & 1.00 & 7.3479 & 6.4 \\
\hline 33 & 10.4037 & 8.8645 & 0.83 & 0.97 & 9.7412 & 8.3 \\
\hline 34 & 7.7058 & 6.6182 & 0.99 & 1.15 & 7.2012 & 6.2 \\
\hline 35 & 8.4669 & 7.2142 & 0.92 & 1.08 & 7.9534 & 6.8 \\
\hline 36 & 7.6704 & 6.5878 & 0.94 & 1.09 & 7.2051 & 6.2 \\
\hline 37 & 20.5656 & 17.2049 & 0.77 & 0.92 & 19.3175 & 16.2 \\
\hline
\end{tabular}


Continued

\begin{tabular}{|c|c|c|c|c|c|c|}
\hline 38 & 16.9265 & 14.2303 & 0.79 & 0.93 & 15.8909 & 14.9 \\
\hline 39 & 13.8254 & 11.6231 & 0.88 & 1.05 & 12.9545 & 12.3 \\
\hline 40 & 13.1701 & 11.1576 & 0.78 & 0.92 & 12.3575 & 11.9 \\
\hline 41 & 24.9434 & 20.7226 & 0.85 & 1.03 & 23.4343 & 19.5 \\
\hline 42 & 19.6055 & 16.3457 & 0.88 & 1.06 & 18.4211 & 15.1 \\
\hline 43 & 10.54 & 8.9294 & 0.83 & 0.97 & 9.8632 & 8.1 \\
\hline 44 & 10.4035 & 9.2183 & 0.83 & 0.93 & 9.7249 & 8.6 \\
\hline 45 & 9.9188 & 8.2979 & 1.05 & 1.25 & 9.3384 & 7.8 \\
\hline 46 & 7.7967 & 7.9695 & 1.03 & 1.00 & 7.2819 & 7.4 \\
\hline 47 & 18.0297 & 17.8159 & 0.97 & 0.98 & 16.8329 & 16.6 \\
\hline 48 & 10.1525 & 8.4934 & 1.05 & 1.26 & 9.5514 & 8.0 \\
\hline 49 & 17.4376 & 17.1769 & 0.97 & 0.98 & 16.2713 & 16.0 \\
\hline 50 & 15.5252 & 15.5524 & 1.03 & 1.03 & 14.4886 & 14.5 \\
\hline 51 & 17.3498 & 17.7343 & 1.00 & 0.98 & 16.1790 & 16.5 \\
\hline 52 & 12.354 & 12.1234 & 1.04 & 1.06 & 11.4931 & 11.3 \\
\hline 53 & 11.2788 & 11.0171 & 1.12 & 1.14 & 10.2624 & 9.1 \\
\hline 54 & 12.2977 & 12.5703 & 0.94 & 0.92 & 11.4819 & 11.7 \\
\hline 55 & 10.8717 & 11.1127 & 1.09 & 1.07 & 10.0317 & 8.9 \\
\hline 56 & 17.3573 & 17.4199 & 1.01 & 1.01 & 16.2012 & 16.3 \\
\hline 57 & 19.2333 & 19.6596 & 1.10 & 1.07 & 17.8932 & 18.3 \\
\hline 58 & 13.6384 & 13.9407 & 1.10 & 1.08 & 12.7200 & 13.0 \\
\hline 59 & 14.3381 & 14.29 & 0.93 & 0.93 & 13.4207 & 13.4 \\
\hline 60 & 13.4991 & 13.4538 & 1.01 & 1.01 & 12.5911 & 12.5 \\
\hline 61 & 15.4251 & 14.6219 & 1.07 & 1.13 & 14.4485 & 14.7 \\
\hline 62 & 14.6248 & 14.2855 & 1.05 & 1.07 & 13.6487 & 13.3 \\
\hline 63 & 14.2315 & 14.1838 & 0.93 & 0.94 & 13.2930 & 13.2 \\
\hline 64 & 14.4434 & 14.395 & 0.93 & 0.93 & 13.4916 & 13.4 \\
\hline 65 & 8.3784 & 8.5641 & 1.04 & 1.02 & 7.8201 & 8.0 \\
\hline 66 & 8.9317 & 9.1297 & 1.04 & 1.02 & 8.3523 & 8.5 \\
\hline 67 & 16.3601 & 16.4191 & 0.97 & 0.96 & 15.2564 & 15.3 \\
\hline 68 & 16.9358 & 15.9283 & 0.93 & 0.99 & 15.8278 & 13.4 \\
\hline 69 & 17.0702 & 16.287 & 0.85 & 0.89 & 16.1040 & 16.3 \\
\hline 70 & 15.5725 & 14.858 & 0.92 & 0.96 & 14.5969 & 13.6 \\
\hline 71 & 18.2023 & 17.9864 & 1.00 & 1.01 & 16.9797 & 14.4 \\
\hline 72 & 16.2701 & 16.3288 & 1.04 & 1.04 & 15.1739 & 13.1 \\
\hline 73 & 9.576 & 9.7882 & 0.93 & 0.91 & 8.8834 & 9.1 \\
\hline 74 & 16.6829 & 16.7431 & 1.02 & 1.02 & 15.5687 & 15.6 \\
\hline 75 & 19.6911 & 20.1275 & 1.05 & 1.02 & 18.3850 & 15.4 \\
\hline 76 & 15.4355 & 15.7776 & 1.06 & 1.03 & 14.3828 & 14.4 \\
\hline 77 & 12.1126 & 11.7629 & 0.92 & 0.95 & 11.2379 & 10.5 \\
\hline
\end{tabular}


Continued

\begin{tabular}{|c|c|c|c|c|c|c|}
\hline 78 & 18.2586 & 18.3766 & 1.06 & 1.06 & 17.0269 & 17.1 \\
\hline 79 & 20.2064 & 18.5918 & 0.93 & 1.01 & 18.9263 & 17.4 \\
\hline 80 & 11.4603 & 10.9345 & 1.00 & 1.05 & 10.6949 & 10.2 \\
\hline 81 & 13.6196 & 13.2264 & 0.93 & 0.95 & 12.7310 & 13.0 \\
\hline 82 & 17.5189 & 16.2816 & 0.83 & 0.90 & 16.3308 & 15.2 \\
\hline 83 & 15.5873 & 14.66 & 0.87 & 0.93 & 14.5106 & 13.9 \\
\hline 84 & 13.8437 & 13.2085 & 0.92 & 0.97 & 12.8623 & 10.9 \\
\hline 85 & 14.6034 & 14.9271 & 1.02 & 1.00 & 13.6477 & 14.0 \\
\hline 86 & 13.1729 & 12.7926 & 0.96 & 0.98 & 12.2962 & 10.5 \\
\hline 87 & 13.5546 & 13.1633 & 0.93 & 0.96 & 12.6671 & 12.3 \\
\hline 88 & 22.6612 & 23.1635 & 1.00 & 0.98 & 21.1151 & 21.6 \\
\hline 89 & 18.2592 & 16.9696 & 0.95 & 1.03 & 17.1053 & 15.9 \\
\hline 90 & 11.5674 & 11.4864 & 0.89 & 0.90 & 10.8043 & 10.7 \\
\hline 91 & 12.9318 & 13.2184 & 0.96 & 0.94 & 12.0376 & 12.3 \\
\hline 92 & 12.8689 & 13.1541 & 0.99 & 0.97 & 11.9701 & 12.2 \\
\hline 93 & 14.8622 & 15.1916 & 1.06 & 1.04 & 13.8765 & 14.2 \\
\hline 94 & 15.2383 & 15.576 & 1.06 & 1.04 & 14.3751 & 14.7 \\
\hline 95 & 15.4103 & 15.7518 & 1.05 & 1.03 & 14.4006 & 13.7 \\
\hline 96 & 16.3088 & 16.6703 & 1.09 & 1.06 & 15.2360 & 15.6 \\
\hline 97 & 17.1266 & 17.5062 & 1.02 & 1.00 & 15.9001 & 15.4 \\
\hline 98 & 11.2641 & 11.5138 & 0.94 & 0.92 & 10.4851 & 10.0 \\
\hline 99 & 8.7455 & 7.1541 & 0.80 & 0.98 & 8.2032 & 6.7 \\
\hline 100 & 11.8776 & 9.7162 & 0.86 & 1.05 & 11.1466 & 9.1 \\
\hline 101 & 11.8508 & 9.6943 & 0.93 & 1.13 & 11.1610 & 9.1 \\
\hline 102 & 10.5161 & 8.6025 & 0.81 & 0.99 & 9.8764 & 8.4 \\
\hline 103 & 7.0548 & 6.4911 & 0.91 & 0.99 & 6.6022 & 6.1 \\
\hline 104 & 17.7988 & 15.2866 & 0.80 & 0.94 & 16.6893 & 14.3 \\
\hline 105 & 14.0043 & 12.1706 & 0.79 & 0.91 & 13.1325 & 11.4 \\
\hline 106 & 14.6858 & 12.6796 & 0.82 & 0.95 & 13.8034 & 11.9 \\
\hline 107 & 12.0338 & 11.2477 & 0.95 & 1.01 & 11.2562 & 9.3 \\
\hline 108 & 12.4057 & 10.8718 & 0.83 & 0.95 & 11.6537 & 10.2 \\
\hline 109 & 8.7048 & 7.8315 & 0.91 & 1.01 & 8.1405 & 7.3 \\
\hline 110 & 17.9867 & 15.448 & 0.83 & 0.96 & 16.8834 & 16.8 \\
\hline 111 & 16.1562 & 13.9491 & 0.81 & 0.94 & 15.1430 & 13.1 \\
\hline 112 & 11.1266 & 9.7508 & 0.89 & 1.02 & 10.4099 & 10.7 \\
\hline 113 & 10.7257 & 10.5985 & 0.93 & 0.94 & 9.9975 & 9.9 \\
\hline 114 & 15.7348 & 15.7623 & 1.00 & 1.00 & 14.6754 & 14.7 \\
\hline 115 & 10.604 & 10.4782 & 0.94 & 0.95 & 9.8864 & 9.8 \\
\hline 116 & 15.4225 & 15.4495 & 1.02 & 1.02 & 14.3652 & 14.7 \\
\hline 117 & 13.65 & 13.9525 & 1.03 & 1.01 & 12.7079 & 12.4 \\
\hline 118 & 8.5846 & 8.7749 & 0.93 & 0.91 & 7.9981 & 8.2 \\
\hline
\end{tabular}




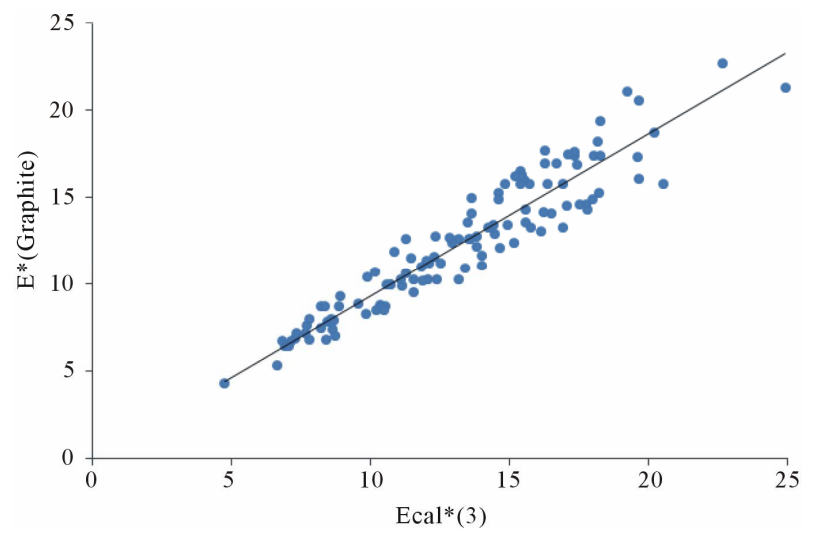

Figure 1. Experimental organic molecule-graphitic surface binding energies versus three layer calculated binding energies for 118 adsorbate molecules gave a linear regression of $E^{*}($ graphite $)=0.9321$ Ecal*(3) with $\left(R^{2}=0.8906\right)$.

Table 3. Number of data points, the slope, and the $R^{2}$ values for each group. The data points available within a group varied from a low of 4 molecules in the cycloalkane category to a high of 24 in the benzene derivative category. $R^{2}$ values varied from a low of $\mathbf{0 . 8 7 2 6}$ for cycloalkane to a high of $\mathbf{0 . 9 7 5 6}$ for alkene/alkyne. The slopes varied from a low of 0.8729 for alkane to 1.0312 for chloroaromatic.

\begin{tabular}{cccc}
\hline \multirow{2}{*}{ Functional Group } & \multicolumn{2}{c}{ Parameters } & $\mathrm{n}$ \\
\cline { 2 - 3 } & Slope & $\mathrm{R}^{2}$ & \\
\hline aldehyde & 0.9057 & 0.9308 & 9 \\
alkane & 0.8291 & 0.9971 & 8 \\
alkene/alkyne & 0.8751 & 0.9756 & 7 \\
alkyl alcohol & 0.8564 & 0.9043 & 13 \\
alkyl amine & 0.8288 & 0.96 & 7 \\
ketone & 0.8362 & 0.9421 & 10 \\
cycloalkane & 0.8581 & 0.8726 & 4 \\
aromatic amine & 1.0169 & 0.9394 & 22 \\
benzene & 0.9633 & 0.8971 & 24 \\
chloroaromatic & 1.0312 & 0.9257 & 8 \\
thiophene & 0.9936 & 0.9728 & 6 \\
\hline
\end{tabular}

for aldehyde and were grouped together in what we considered as the "flexible" category. The flexible molecules lacked a flat ring structure in the molecule and so had potentially more conformational flexibility. The average of the slopes in Table 3 for these seven groups was 0.8556 with a 0.0280 standard deviation. When all these "flexible" data $(\mathrm{n}=58)$ are plotted together, the correlating equation is

$$
\mathrm{E}^{*}(\text { graphite })=0.8500 \mathrm{Ecal}^{*}(3)
$$

with $\left(\mathrm{R}^{2}=0.9621\right)$.
While these $\mathrm{R}^{2}$ values of 0.9130 for the rigid and 0.9621 for the flexible molecules are better than the $\mathrm{R}^{2}$ of 0.8906 for all the molecule together, a still better correlation is needed to be able to effectively use Ecal*(3) values to predict $\mathrm{E}^{*}$ (graphite). From the considerations above, it is clear that the calculated values are too high for the "flexible" structures since as shown in Figure 2 the Ecal*(3) values must be multiplied by on average 0.85 to bring their values down to agreement with the $\mathrm{E}^{*}$ (graphite) experimental values. However, there is more variation within individual molecules than simply placing into these two groups.

To reconcile the differences observed for the "rigid" and "flexible" molecules and to have one common equation and one correlation for all the molecules, a different approach was needed. We observed that the MM2 vdW parameters for the $\mathrm{sp}^{3}$ carbon atoms were overestimating their carbon surface interactions and hence could be correlated only by using about $85 \%$ of their estimated binding energy values. The flexible molecule category was dominated by tetrahedral bonded carbons which we label below as $\mathrm{C}-\mathrm{sp}^{3}$ atoms. However, the trigonal planar $\mathrm{sp}^{2}$ carbons dominated the so called rigid molecules had MM2 vdW parameters that matched well with the experimental interaction energies and hence had slopes close to one. In examining the individual molecules we were able to observe variations depending on the number of $\mathrm{C}$-sp ${ }^{3}$ atoms and $\mathrm{C}$-sp ${ }^{2}$ and other atoms. These observations led to the next approach.

In Method IV for every molecule all non-hydrogen atoms were counted and placed into one of two categories. The atom was either a $\mathrm{sp}^{3}$ hybridized carbon or not. The non $\mathrm{sp}^{3}$ carbon atoms included $\mathrm{sp}^{2}$ trigonal planar bonding carbon atoms, sp linear bonding carbon atoms, and all other atoms such as oxygen, nitrogen, sulfur. All hydrogen atoms were excluded from the counting process. So the relations may be summarized as

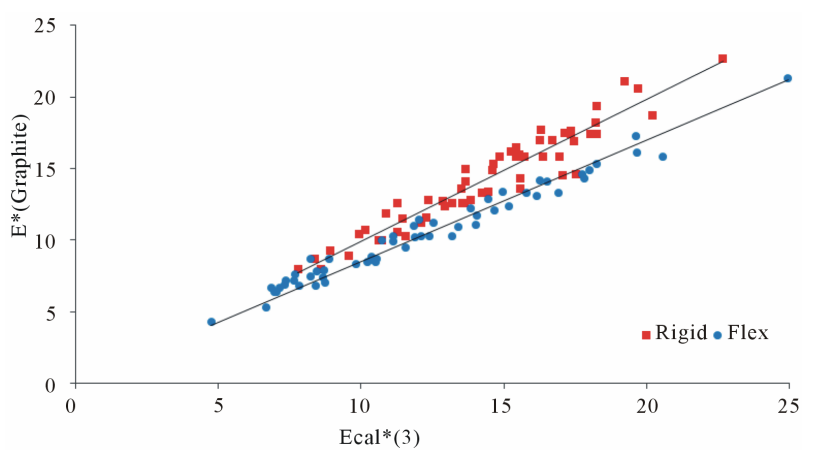

Figure 2. Experimental organic molecule-graphitic surface binding energies versus three layer calculated binding energies for rigid $(n=60)$ and flexible $(n=58)$ adsorbate molecules gave linear regressions of $\mathrm{E}^{*}$ (graphite) $=\mathbf{0 . 9 9 1 8}$ Ecal*(3) with $R^{2}=0.9130$ and $E^{*}$ (graphite) $=0.8500$ Ecal*(3) with $R^{2}=0.9621$, respectively. 


$$
\begin{aligned}
& \mathrm{n}_{\text {total }}=\mathrm{n}_{\mathrm{C}-\mathrm{sp} 3}+\mathrm{n}_{\text {other }} \\
& \mathrm{f}_{\mathrm{C} \text {-sp3 }}=\mathrm{n}_{\mathrm{C}-\mathrm{sp} 3} / \mathrm{n}_{\text {total }} \\
& \mathrm{f}_{\text {other }}=\mathrm{n}_{\text {other }} / \mathrm{n}_{\text {total }} \\
& 1=\mathrm{f}_{\text {C-sp3 }}+\mathrm{f}_{\text {other }}
\end{aligned}
$$

where $n_{\text {total }}$ is the total number of nonhydrogen atoms, $\mathrm{n}_{\mathrm{C} \text {-sp3 }}$ is the number of $\mathrm{sp}^{3}$ carbon atoms, $\mathrm{n}_{\text {other }}$ is the number of all other nonhydrogen and non $\mathrm{sp}^{3}$ carbon atoms, $\mathrm{f}_{\mathrm{C}-\mathrm{sp} 3-\mathrm{c}}$ is the fraction of $\mathrm{sp}^{3}$ carbon atoms, and $\mathrm{f}_{\text {other }}$ is the fraction of all other nonhydrogen atoms.

Using the above relations then the Equation (3) may be written as

$$
\mathrm{E}^{*}(\text { graphite })=\left(\mathrm{c}_{\mathrm{C} \text {-sp3 }} \mathrm{f}_{\mathrm{C} \text {-sp3 }}+\mathrm{c}_{\text {other }} \mathrm{f}_{\text {other }}\right) \text { Ecal* }{ }^{*}(3)
$$

$\mathrm{c}_{\mathrm{C} \text {-sp3 }}$ and $\mathrm{c}_{\text {other }}$ are the best fit coefficients multiplied by the fraction of $\mathrm{sp}^{3}$ carbon atoms and fraction of other non-hydrogen atoms, respectively. The $\alpha$ term in Equation (3) is now represented as $\alpha=\left(\mathrm{c}_{\mathrm{C} \text {-sp3 }} \mathrm{f}_{\mathrm{C} \text {-sp3 }}+\mathrm{c}_{\text {other }}\right.$ $\left.\mathrm{f}_{\text {other }}\right)$. The $\mathrm{c}_{\mathrm{C} \text {-sp3 }}$ and $\mathrm{c}_{\text {other }}$ were derived from multilinear regression calculation using $\mathrm{E}^{*}$ (graphite) and $\mathrm{Ecal}^{*}(3)$ values in Table 1 along with $f_{C \text {-sp3 }}$ and $f_{\text {other }}$ values for each of the 118 molecules. The best fit coefficients for $\mathrm{c}_{\mathrm{sp} 3-\mathrm{C}}$ was found to be 0.8180 and for $\mathrm{c}_{\mathrm{other}}$ was found to be 1.0221 .

The originally calculated Ecal*(3) for each of the 118 molecules could then be modified by the equation for $\alpha$ in Equation (14) and are given in Table 2. These modified values are indicated as Ecal*(3)-modified. For example, consider the molecule 1,2,3,5-tetramethylbenzene that consist of $4 \mathrm{sp}^{3}$ carbon atoms and $6 \mathrm{sp}^{2}$ carbon atoms. The fractions are $\mathrm{f}_{\mathrm{C} \text {-sp3 }}=0.4000$ and $\mathrm{f}_{\text {other }}=0.6000$. Using the best fit values of the fractions $\mathrm{c}_{\mathrm{sp} 3-\mathrm{C}}$ gives $[(0.8180)(0.4000)+(1.0221)(0.6000)] 16.9358 \mathrm{kcal} /$ $\mathrm{mol}=[0.9405][16.9358]=15.9274$ or $15.9 \mathrm{kcal} / \mathrm{mol}$. Clearly 15.9 is much better estimate of the reported experimental binding energy of $15.8 \mathrm{kcal} / \mathrm{mol}$.

Figure 3 shows a plot of $E^{*}$ (Graphite) versus Ecal*(3)modified where

$$
\begin{aligned}
& \text { Ecal*(3)-modified } \\
& =\left(0.8180 \mathrm{f}_{\mathrm{C} \text {-sp3 }}+1.0221 \mathrm{f}_{\text {other }}\right) \operatorname{Ecal} *(3)
\end{aligned}
$$

The linear regression for $\mathrm{E}^{*}$ (graphite) versus Ecal*(3)modified $(\mathrm{n}=118)$ gave a slope of 1.0000 and $\left(\mathrm{R}^{2}=\right.$ 0.9647). While still using the standard MM2 parameters this approach provides a fairly simple modification that provides reasonable estimates of $\mathrm{E}^{*}$ (graphite). A comparison of Figures 1 and $\mathbf{3}$ shows a change of $\mathrm{R}^{2}$ from 0.8906 to 0.9647 indicating a significant improvement in the correlation.

Next, it was necessary to determine values of Ecal*(1). A molecule must have same placement and orientation for accurate comparison. The only part that should be different was the number of layers for the surface. To convert graphite to graphene, the second and third layers were removed from molecules already placed on the graphite model using the procedure previously described. The $E_{m s}$ was recalculated for each molecule after MM2 optimization and then used with $\mathrm{E}_{\mathrm{m}}$ values and an $\mathrm{E}_{\mathrm{s}}$ (graphene) calculated value to find Ecal*(1) using Equation (1). The average ratio of Ecal*(1)/Ecal*(3) for the 118 molecules gave an average and standard deviation of $0.9350 \pm 0.004$. Figure 4 shows a plot of Ecal*(1) versus Ecal*(3) and the slope based on a linear regression was 0.9349 with $\left(\mathrm{R}^{2}=0.9998\right)$. The results indicated the calculated binding energy of a molecule on graphene is consistently $93.5 \%$ of the calculated value on graphite. Thus, the $\beta$ from Equation (4) is determined to be 0.935 and may the relation may be expressed as

$$
\text { Ecal } *(1)=0.935 \text { Ecal } *(3)
$$

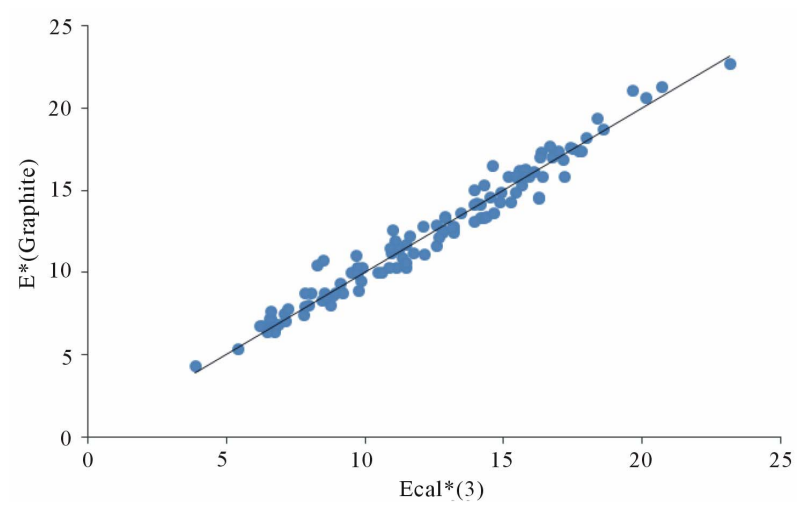

Figure 3. Experimental organic molecule-graphitic surface binding energies versus modified three layer calculated binding energies for 118 adsorbate molecules gave a linear regression of $E^{*}$ (graphite) $=1.0000$ Ecal $*(3)$-modified $(n$ =118) with $\left(R^{2}=0.9647\right)$.

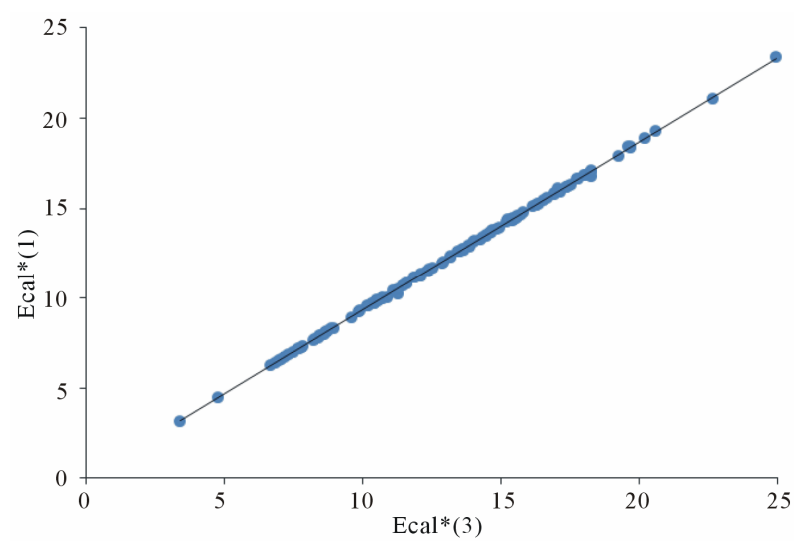

Figure 4. Plot of Ecal*(1) modeling binding energy on graphene versus Ecal*(3) modeling binding energies on graphite for 118 organic adsorbate molecules gave a linear regression with a slope of 0.9349 and $\left(R^{2}=0.9998\right)$. 
So we propose that using MM2 parameters for a molecule in optimized geometry and then placed on a three layer graphite surface can give a reasonable estimate of the graphene binding energy using our Equation (6) expressed after combining Equations (14) and (15) to give

$$
\begin{aligned}
& \mathrm{E}^{*}(\text { graphene }) \\
& =0.935\left[0.8180 \mathrm{f}_{\mathrm{C}-\mathrm{sp} 3}+1.0221 \mathrm{f}_{\text {other }}\right] \mathrm{Ecal}^{*}(3)
\end{aligned}
$$

Or more directly if a molecule is placed on a single layer model graphene surface, a reasonable estimate of the expected molecule-graphene interaction or binding energy is obtained from

$$
\begin{aligned}
& \mathrm{E}^{*}(\text { graphene }) \\
& =\left[0.8180 \mathrm{f}_{\mathrm{C}-\mathrm{sp} 3}+1.0221 \mathrm{f}_{\text {other }}\right] \mathrm{Ecal}^{*}(1)
\end{aligned}
$$

It is assumed that the graphite correction also can be applied to graphene. This assumption is reasonable considering a single carbon layer accounts for $93.5 \%$ of the MM2 graphite binding energies for the 118 molecules considered. The $\mathrm{c}_{\mathrm{Csp} 3}$ and $\mathrm{c}_{\text {other }}$ above are taken directly from Equation (15). The $\alpha$ in Equation (3) is now represented from the above as $\alpha=\left(\mathrm{c}_{\mathrm{C}-\mathrm{sp} 3} \mathrm{f}_{\mathrm{C}-\mathrm{sp} 3}+\mathrm{c}_{\text {other }} \mathrm{f}_{\text {other }}\right)$.

\section{Discussion}

The binding energy of an adsorbate molecule on an adsorbent surface can be affected by molecule size, molecule orientation, and the nature of surface. For organic molecules adsorbed on graphitic surfaces, van der Waals forces tend to dominate the physical adsorption. Larger more polarizable atoms tend to increase $\mathrm{vdW}$ forces increase the binding energy. For example, comparing molecules M91 1,3-dichlorobenzene and M73 benzene, one observes $E^{*}$ values of 12.4 and $8.9 \mathrm{kcal} / \mathrm{mol}$, respectively. More atoms in a molecule increases the vdW forces. For example, comparing molecules M12 decane and M11 butane, one observes $\mathrm{E}^{*}$ values of 16.1 and $6.8 \mathrm{kcal} / \mathrm{mol}$, respectively. Different orientations of the molecule and different conformations can also affect the binding energy. Orientations of molecules were selected to have the maximum contact with the surface. Since our focus was to find the lowest energy for a molecule adsorbed on a surface, we chose the most polarizable atom facing the surface as previously described because the $\mathrm{vdW}$ is stronger with more polarizable atoms near the surface and a flat orientation to put as much of the molecule on the surface as possible.

The approach illustrated in Table 3 was to divide the experimental values into one of nine subgroups based on the molecular structure of the adsorbate. With the exception of the cycloalkane group that only had four molecules and $\mathrm{R}^{2}=0.8726$, all the remaining $\mathrm{R}^{2}$ values were better than the set of all 118 molecules with $\mathrm{R}^{2}=0.8906$. The $\mathrm{R}^{2}$ for the eight other groups ranged from 0.8971 up to 0.9971 . However it was desirable to have one general equation that would allow calculation of Ecal* for whatever molecule was selected without regard to functional group.

As shown in Table 2, our coefficients and the equation do not make our Ecal* values match with $\mathrm{E}^{*}$ exactly. However, our modification provides a reasonable approach to interpret the over-calculated values for the atoms with $\mathrm{sp}^{3}$ hybridizations and improves the match of calculated and experimental values. Using the values of the $\mathrm{E}^{*} / \mathrm{Ecal}{ }^{*}(3)$ ratios gives an average of 0.93 and a 0.09 standard deviation. Using the values of the $\mathrm{E}^{* /}$ Ecal*(3)-modified ratios gives an average of 1.01 and 0.07 standard deviation. This modification was necessary to successfully predict the binding energy. Figure 1 shows the $\mathrm{E}^{*}$ versus Ecal* plots somewhat scattered with $\mathrm{R}^{2}$ of 0.8906 and a slope of 0.9321 . However, Figure 3 shows $E^{*}$ versus Ecal*(3)-modified with a slope of 1.0000 and $\mathrm{R}^{2}$ of 0.9647 . So Equation (15) provides an effective method to estimate $E^{*}$ (graphite) by modifying computed values of Ecal*(3). There is a regular relation between $\mathrm{Ecal}^{*}(1)$ and $\mathrm{Ecal}^{*}(3)$ with the Ecal*(1) values being $93.5 \%$ of the Ecal*(3) values as shown in Figure 4 and in Table 2.

Our initial adjustment for the scatter in Figure 1 was to place molecules in categories of rigid (ring containing) or flexible (no ring) as illustrated in Table 3 based on the slopes that were near one for aromatic amine, benzene derivatives, chloroaromatic, and thiophene groups but clearly less than one for the remaining seven groups. While this division into two categories led to improved correlation coefficients with $\mathrm{R}^{2}$ equal to 0.9621 and 0.9130 for the flexible and rigid, respectively the cause of this difference was based on the overestimate of $\mathrm{vdW}$ forces between the surface carbon atoms and $\mathrm{sp}^{3}$ carbon atoms. For instance, Table 2 shows the ratio of $\mathrm{E}^{*}$ (graphite)/Ecal*(3) is 0.87 for n-butyl benzene (M83) but for naphthalene (M85) this ratio is 1.02 meaning the calculated and experimental are in close agreement. Both molecules have same number of carbons but the Ecal* is about $15 \%$ too large due to the calculated vdW energy being too high.

Since this overestimation occurs in a regular pattern we were able to adjust the Ecal* simply based on the fraction of nonhydrogen atoms that were $\mathrm{sp}^{3}$ carbon atoms. This adjustment was accomplished by Equation (15) where the fraction of $\mathrm{sp}^{3}$ carbons is multiplied by 0.8180 Ecal* to give its $\mathrm{E}^{*}$ contribution to $\mathrm{E}^{*}$ and the fraction of all other nonhydrogen atoms is multiplied by 1.0221 Ecal* to give its contribution to $\mathrm{E}^{*}$. We see that on average $\mathrm{sp}^{3}$ carbons have a value that is too high and all other nonhydrogen atoms have values that are on average 
slightly low.

To test the application of our approach a molecule not in the original set of 118 molecules was selected for estimation of $\mathrm{E}^{*}$ (graphite) and $\mathrm{E}^{*}$ (graphene). C. Thierfelder et al. reported calculated binding energies of methane on graphene with five different methods [44]. They used a reported experimental value of methane on graphite in the range of $0.12-0.14 \mathrm{eV}$. They also made an assumption that the binding energy of methane on graphene should be about $0.01 \mathrm{eV}$ less than on graphite so their estimated binding energy value for methane on graphite was $\mathrm{E}^{*}$ (graphite) $=0.12$ to $0.14 \mathrm{eV}$ and on graphene they estimated $\mathrm{E}^{*}$ (graphene) $=0.11$ to $0.13 \mathrm{eV}$. Our estimated energy for Ecal*(3) for methane was 3.40 $\mathrm{kcal} / \mathrm{mol}$ and Ecal*(3)-modified was $2.8 \mathrm{kcal} / \mathrm{mol}(0.12$ $\mathrm{eV}$ ) and the predicted Ecal*(graphite) was $2.6 \mathrm{kcal} / \mathrm{mol}$ $(0.11 \mathrm{eV})$. So our estimated binding energies of

$\mathrm{E}^{*}($ graphite $)=0.12 \mathrm{eV}$ and $\mathrm{E}^{*}($ graphene $)=0.11 \mathrm{eV}$ agree with well their suggested values.

\section{Conclusions}

The weakness of noncovalent vdW interactions presents a general challenge for more exact quantum mechanical methods and density functional theory (DFT) calculations as indicated by a comparison of 40 density functionals with noncovalent interaction energies $[45,46]$. DFT results have been reported to underestimate vdW interactions [47]. However, Moller-Plesset perturbation theory (MP2) has been reported to overestimate the binding energies [48]. The basis set used to model a molecule and a dimer cluster (benzene-coronene for example) can greatly affect the interaction energy. This error is known as the basis set superposition error (BSSE). For benzene-coronene quantum calculations where coronene can be used to represent a graphene surface the MP2 results had to be modified by a counterpoise correction of about $40 \%$ [48]. Tauer and Sherrill examined $\pi-\pi$ interactions for benzene dimers and trimmers and found that MP2 calculations with small basis sets tended to have cancelling errors. By allowing these errors to offset each other they were able to find interaction energies close, few tenths of $\mathrm{kcal} / \mathrm{mol}$, of a complete basis set couple cluster $\operatorname{CCSD}(\mathrm{T})$ limit [49]. Because of these computational challenges, for ease of use, for representations of larger surface areas or multiple molecules, and for simpler and quicker calculations it can be useful to make estimates based on molecular mechanics and the approach outlined in this work.

We used augmented MM2 parameters and classical molecular modeling to predict molecule-graphene binding energies of 118 organic molecules. Our results suggest that this method can provide useful estimates of experimental values that may otherwise be difficult to obtain. In prior work MM2 parameters and molecular me- chanics calculations have been used to estimate molecule surface interaction energies on flat, rough, and porous carbon surfaces [22-25,43].

The calculated binding energies for a molecule on the single layer graphene model were consistently found to be $93.5 \%$ of the value for the same molecule on the three-layer graphite model. This is in agreement with prior work for nucleobases on graphene and graphite that showed going from 1 to 3 layers increased binding energy by $8 \%$ to $10 \%$ [43]. The MM2 calculations for these binding energies are dominated by $\mathrm{vdW}$ forces and these have been observed to give reasonable correlations when a standard $0.9 \mathrm{~nm}$ cutoff value was used. One implication for future sensor devices based on adsorption due to dispersive forces on bilayer graphene is that the interaction energy for a bilayer should be very close, within a few percent, to the value for graphite.

Although the MM2 parameters were not optimized for adsorption energy calculations, the values obtained for $\mathrm{vdW}$ dominated adsorption on carbon give good correlations with experimental. It was observed that calculated Ecal* values had to be corrected to better agree with the experimental $\mathrm{E}^{*}$ for the set of 118 organic molecules used. The calculated binding energy was corrected with simple modification using coefficients that reduced the energy contribution from all $\mathrm{sp}^{3}$ carbon atoms by multiply the fraction of these atoms by 0.818 and the remaining carbon and heteroatoms (hydrogen atoms were not included in determining these fractions) were almost unchanged being multiplied by 1.022 , respectively.

The direct MM2 results gave the ratio of $\mathrm{E}^{*} / \mathrm{Ecal}^{*}(3)$ as $0.93(\mathrm{n}=118)$ with a standard deviation of 0.09 . The modified MM2 results gave the ratio of $\mathrm{E}^{*} / \mathrm{Ecal}^{*}(3)$-mod as $1.01(\mathrm{n}=118)$ with a standard deviation of 0.07 . So the direct MM2 model based binding energies were on average larger than the experimental values by about $7.5 \%(1 / 0.93=1.075)$, but after the modification described previously and given in Equation (15), the average of all 118 values was within about one percent. Most calculated values were within $7 \%$ of the corresponding experimental ones (see Table 2). The slope of $\mathrm{E}^{*}$ versus Ecal*(3)-mod was 1.00 with $\mathrm{R}^{2}=0.965$ as shown in Figure 3.

The modification of the Ecal*(3) calculated values should apply to the graphene also so the Ecal*(3)-mod could be multiplied by 0.935 as shown in Equation (16) to find $\mathrm{E}^{*}$ (graphene). Or more directly Ecal*(1) can be converted to $E^{*}$ (gaphene) using Equation (17). In other words, a molecule's interaction energy can be calculated on a three layer model or a one layer model and effectively converted to a reasonable estimate of the expected experimental interaction energy on single layer graphene surface, $E^{*}$ (graphene). Using our data set correlations and extending it to a molecule not included in the origin- 
nal set of 118 allowed us to test this method. Binding energies of 0.12 and $0.11 \mathrm{eV}$ were obtained for methane and these compared well to published experimental and estimated values for graphite and graphene, respectively.

Simpler non quantum mechanical calculations based on classical molecular mechanics continue to be of use to estimate molecule-surface binding energies based on weaker dispersion forces. This molecular mechanics approach does not provide any electronic details but it is a useful, computationally simple approach to study molecule interactions on carbon surfaces and should be helpful to predict how strongly various molecules may be held on future single layer graphene or bilayer graphene sensor detection devices. This approach may also be useful to predict interactions in other possible applications such as surface self assembly, molecular separations, or graphene-molecule storage and delivery devices.

\section{Acknowledgements}

We gratefully acknowledge the support provided by the Grote Chemistry Fund and the Wheeler Odor Research Center at the University of Tennessee at Chattanooga.

\section{REFERENCES}

[1] S. W. Pati, T. Enoki and C. N. Rao, "Graphene and Its Fascinating Attributes," World Scientific, Singapore, 2011.

[2] W. Choi and J. Lee, "Graphene: Synthesis and Applications," CRC Press, Boca Raton, 2012.

[3] Royal Swedish Academy of Sciences, "Scientific Background on the Nobel Prize in Physics 2010 GRAPHENE," 2010.

http://www.nobelprize.org/nobel_prizes/physics/laureates /2010/advancedphysicsprize2010.pdf

[4] P. T. Araujo, M. Terrones and M. S. Dresselhaus, "Defects and Impurities in Graphene-Like Materials," Materials Today, Vol. 15, No. 3, 2012, pp. 98-109. doi:10.1016/S1369-7021(12)70045-7

[5] W. Choi, I. Lahiri, R. Seelaboyina and Y. S. Kang, "Synthesis of Graphene and Its Applications: A Review," Critical Reviews in Solid State Materials Sciences, Vol. 35, No. 1, 2010, pp. 52-71. doi:10.1080/10408430903505036

[6] H. J. Yoon, D. H. Jun, J. H. Yang, Z. Zhou, S. S. Yang and M. M.-C. Chen, "Carbon Dioxide Gas Sensor Using a Graphene Sheet," Sensors and Actuators B: Chemical, Vol. 157, No. 1, 2011, pp. 310-313.

doi:10.1016/j.snb.2011.03.035

[7] Y. Zou, F. Li, Z. H. Zhu, M. W. Zhao, X. G. Xu and X. Y. $\mathrm{Su}$, "An ab Initio Study on Gas Sensing Properties of Graphene and Si-Doped Graphene," European Physical Journal B, Vol. 81, No. 4, 2011, pp. 475-479. doi:10.1140/epjb/e2011-20225-8

[8] O. Leenaerts, B. Partoens and F. M. Peeters, "Adsorption of $\mathrm{H}_{2} \mathrm{O}, \mathrm{NH}_{3}, \mathrm{CO}, \mathrm{NO}_{2}$, and $\mathrm{NO}$ on Graphene: A FirstPrinciples Study," Physical Review B, Vol. 77, No. 12,
2008, Article ID: 125416. doi:0.1103/PhysRevB.77.125416

[9] M. Gautam and A. H. Jayatissa, "Adsorption Kinetics of Ammonia Sensing by Graphene Films Decorated with Platinum Nanoparticles," Journal of Applied Physics, Vol. 111, No. 9, 2012, Article ID: 094317. doi:10.1063/1.4714552

[10] Y. Ren, C. Zhu, W. Cai, H. Li, H. Ji, I. Kholmanov, Y. Wu, R. D. Piner and R. S. Ruoff, "Detection of Sulfur Dioxide Gas with Graphene Field Effect Transistor," $A p$ plied Physics Letters, Vol. 100, No. 16, 2012, Article ID: 163114. doi:10.1063/1.4704803

[11] M. G. Chung, D. H. Kim, H. M. Lee, T. Kim, J. H. Choi, D. K. Seo, J.-B. Yoo, S.-H. Hong, T. J. Kang and Y. H. Kim, "Highly Sensitive $\mathrm{NO}_{2}$ Gas Sensor Based on Ozone Treated Graphene," Sensors and Actuators B: Chemical, Vol. 166-167, 2012, pp. 172-176. doi:10.1016/j.snb.2012.02.036

[12] S. Mao, S. Cui, G. Lu, K. Yu, Z. Wen and J. Chen, "Tuning Gas-Sensing Properties of Reduced Graphene Oxide Using Tin Oxide Nanocrystals," Journal of Materials Chemistry, Vol. 22, 2012, pp. 11009-11013. doi:10.1039/c2jm30378g

[13] H. Zhang, A. Kulkarni, H. Kim, D. Woo, Y.-J. Kim, B. H. Hong, J.-B. Choi and T. Kim, "Detection of Acetone Vapor Using Graphene on Polymer Optical Fiber," Journal of Nanoscience and Nanotechnology, Vol. 11, No. 7, 2011, pp. 5939-5943. doi:10.1166/jnn.2011.4408

[14] T. V. Cuong, V. H. Pham, J. S. Chung, E. W. Shin, D. H. Yoo, S. H. Hahn, J. S. Huh, G. H. Rue, E. J. Kim, S. H. Hur and P. A. Kohl, "Solution-Processes ZnO-Chemically Converted Graphene Gas Sensor," Materials Letters, Vol. 64, No. 22, 2010, pp. 2479-2482. doi:10.1016/j.matlet.2010.08.027

[15] J. L. Johnson, A. Behnam, S. J. Pearton and A. Ural, "Hydrogen Sensing Using Pd-Functionalized Multi-Layer Graphene Nanoribbon Networks," Advanced Materials, Vol. 22, No. 43, 2010, pp. 4877-4880. doi:10.1002/adma.201001798

[16] W. Wu, Z. Liu, L. A. Jauregui, Q. Yu, R. Pillai, H. Cao, J. Bao, Y. P. Chen and S.-S. Pei, "Wafer-Scale Synthesis of Graphene by Chemical Vapor Deposition and Its Application in Hydrogen Sensing," Sensors and Actuators B: Chemical, Vol. 150, No. 1, 2010, pp. 296-300. doi:0.1016/j.snb.2010.06.070

[17] H. Song, L. Zhang, C. He, Y. Qu, Y. Tian and Y. Lv, "Graphene Sheets Decorated with $\mathrm{SnO}_{2}$ NanoParticles: In Situ Synthesis and Highly Efficient Materials for Cataluminescence Gas Sensors," Journal of Materials Chemistry, Vol. 21, No. 16, 2011, pp. 5972-5977. doi:10.1039/c0jm04331a

[18] A. Shimizu and K. Fujii, "Thin Film Gas Sensor,” Japan Kokai Tokyo Koho, 2011, JP 2011169634 A 20110901.

[19] G. Lu, S. Park, K. Yu, R. S. Ruoff, L. E. Ocola, D. Rosenmann and J. Chen, "Toward Practical Gas Sensing with Highly Reduced Graphene Oxide: A New Signal Processing Method to Circumvent Run-to-Run and Device-to-Device Variations," ACS Nano, Vol. 5, No. 2, 2011, pp. 1154-1164. doi:10.1021/nn102803q 
[20] G. Lu, L. E. Ocola and J. Chen, "Gas Detection Using Low-Temperature Reduced Graphene Oxide Sheets," Applied Physics Letters, Vol. 94, No. 8, 2009, Article ID: 083111. doi:10.1063/1.3086896

[21] T. R. Rybolt, C. E. Wells, C. R. Sisson, C. B. Black and K. A. Ziegler, "Evaluation of Molecular Mechanics Calculated Binding Energies for Isolated and Monolayer Organic Molecules on Graphite," Journal of Colloid and Interface Science, Vol. 314, No. 2, 2007, pp. 434-445. doi:10.1016/j.jcis.2007.05.083

[22] T. R. Rybolt, K. A. Ziegler, H. E. Thomas, J. L. Boyd and M. E. Ridgeway, "Adsorption Energies for a Nanoporous Carbon from Gas-Solid Chromatography and Molecular Mechanics," Journal of Colloid and Interface Science, Vol. 296, No. 1, 2006, pp. 41-50. doi:10.1016/j.jcis.2005.08.057

[23] T. R. Rybolt and R. A. Hansel, "Determining MoleculeCarbon Surface Adsorption Energies Using Molecular Mechanics and Graphene Nanostructures," Journal of Colloid and Interface Science, Vol. 300, No. 2, 2006, pp. 805-808. doi:10.1016/j.jcis.2006.04.057

[24] T. R. Rybolt, C. E. Wells, H. E. Thomas, C. M. Goodwin, J. L. Blakely and J. D. Turner, "Binding Energies for Alkane Molecules on a Carbon Surface from Gas-Solid Chromatography and Molecular Mechanics," Journal of Colloid and Interface Science, Vol. 325, No. 1, 2008, pp. 282-286. doi:10.1016/i.jcis.2008.06.043

[25] T. R. Rybolt, K. T. Bivona, H. E. Thomas and C. M. O'Dell, "Comparison of Gas-Solid Chromatography and MM2 Force Field Molecular Binding Energies for Greenhouse Gases on a Carbonaceous Surface," Journal of Colloid and Interface Science, Vol. 338, No. 1, 2009, pp. 287292. doi:10.1016/i.jcis.2009.06.001

[26] N. L. Allinger, "Conformational Analysis. 130. MM2. A Hydrocarbon Force Field Utilizing V1 and V2 Torsional Terms," Journal of the American Chemical Society, Vol. 99, No. 25, 1977, pp. 8127-8134. doi:10.1021/ja00467a001

[27] J. Lii and N. L. Allinger, "Molecular Mechanics. The MM3 Force Field for Hydrocarbons. 3. The van der Waals' Potentials and Crystal Data for Aliphatic and Aromatic Hydrocarbons," Journal of the American Chemical Society, Vol. 111, No. 23, 1989, pp. 8576-8582. doi:10.1021/ja00205a003

[28] F. Jensen, "Introduction to Computational Chemistry," John Wiley \& Sons, Chichester, 1999.

[29] E. V. Kalashnikova, A. V. Kiselev, A. M. Makogon and K. D. Shcherbakova, "Adsorption of Molecules of Different Structure on Graphitized Thermal Carbon Black IV. Gas Chromatographic Investigation of Adsorption of Aldehydes, Ketones and Alcohols on Hydrogen-Treated Graphitized Thermal Carbon Black," Chromatographia, Vol. 8, No. 8, 1975, pp. 399-403. doi:10.1007/BF02269088

[30] C. Vidal-Madjar, M. F. Gonnord and G. Guiochon, "Molecular Statistical Theory of Adsorption Prediction of the Thermodynamical Functions of Adsorption of Hydrocarbons on Graphitized Thermal Carbon Black," Journal of Colloid and Interface Science, Vol. 52, No. 1, 1975, pp.

\section{2-119. doi:10.1016/0021-9797(75)90306-9}

[31] O. G. Eisen, A. V. Kiselev, A. E. Pilt, S. A. Rang and K. D. Shcherbakova, "Gas Chromatographic Investigation of Adsorption of Normal Alkenes $\mathrm{C}_{6}-\mathrm{C}_{10}$ on Graphitized Thermal Carbon Black," Chromatographia, Vol. 4, No. 10, 1971, pp. 448-454. doi:10.1007/BF02268813

[32] A. V. Kiselev, E. B. Polotnyuk and K. D. Shcherbakova, "Gas Chromatographic Study of Adsorption of NitrogenContaining Organic Compounds on Graphitized Thermal Carbon Black," Chromatographia, Vol. 14, No. 8, 1981, pp. 478-483. doi:10.1007/BF02263538

[33] S. N. Yashkin, O. B. Grior'eva and A. K. Buryak, "Experimental and Molecular-Statistical Investigation of Adsorption of Aminoadamantanes on Graphitized Thermal Carbon Black," Russian Chemical Bulletin, Vol. 50, No. 6, 2001, pp. 980-985. doi:10.1023/A:1011348730899

[34] S. N. Yashkin, D. A. Svetlov and A. K. Buryak, "Thermodynamic Characteristics of Adsorption of NitrogenContaining Heterocycles on Graphitized Thermal Carbon Black Derived from Molecular Statistical Calculation. 1. Azines," Russian Chemical Bulletin, Vol. 52, No. 2, 2003, pp. 344-353. doi:10.1023/A:1023446513475

[35] E. G. Bychkova, E. V. Kalashnikova, A. V. Kiselev and K. D. Shcherbakova, "Thermodynamic Characteristics of Adsorption of the Naphthalene-Type Hydrocarbons on the Graphitized Thermal Carbon Black," Vestnik Moskovskogo Universiteta, Seriya 2: Khimiya, Vol. 27, No. 4, 1986, pp. 382-385.

[36] E. V. Kalashnikova, A. V. Kiselev, R. S. Petrova, K. D. Shcherbakova and D. P. Poshkus, "Chromatographic Measurements and Molecular Statistical Calculations of Thermodynamic Characteristics of Adsorption of Aromatic and Polycyclic Hydrocarbons on Graphitized Thermal Carbon Black," Chromatographia, Vol. 12, No. 12, 1979, pp. 799-802. doi:10.1007/BF02260661

[37] E. V. Kalashnikova, A. V. Kiselev and K. D. Shcherbakova, "Retention of Some Phenyl-Substituted and Bicyclic Hydrocarbons on Graphitized Carbon Black," Chromatographia, Vol. 17, No. 10, 1983, pp. 521-525. doi:10.1007/BF02261913

[38] A. V. Kiselev, V. I. Nazarova and K. D. Shcherbakova, "Molecular Structure and Retention Behaviour of Some Polycyclic Aromatic and Perhydroaromatic Hydrocarbons on Graphitized Carbon Black," Chromatographia, Vol. 18, No. 4, 1984, pp. 183-189. doi:10.1007/BF02276730

[39] E. V. Kalashnikova, A. V. Kiselev, K. D. Shcherbakova and S. D. Vasileva, "Retention of Diphenyls, Terphenyls, Phenylalkanes and Fluorene on Graphitized Thermal Carbon Black," Chromatographia, Vol.14, No. 9, 1981, pp. 510-514. doi:10.1007/BF02265630

[40] A. K. Buryak, P. B. Dallakyan and A. V. Kiselev, "Determination of Atom-Atom Potentials of Intermolecular Interaction and Calculation of the Thermodynamic Characteristics of Adsorption on Graphite of Sulfur- and Chlorine-Containing Organic Compounds," Doklady Akademii Nauk SSSR Physical Chemistry, Vol. 282, No. 2,1985, pp. 350-353.

[41] A. K. Buryak, A. N. Fedotov and A. V. Kiselev, "Correlation between the Structure of Chlorinated Biphenyls and 
Their Adsorption on Graphitized Thermal Carbon Black," Vestnik Moskovskogo Universiteta, Seriya 2: Khimiya, Vol. 26, No. 6, 1985, pp. 568-571.

[42] W. Engewald, E. V. Kalashnikova, A. V. Kiselev, R. S. Petrova, K. D. Shcherbakova and A. L. Shilov, "Gas Chromatographic Investigation of the Adsorption of Polymethylcyclohexanes on Graphitized Thermal Carbon Black," Journal of Chromatography A, Vol. 152, No. 2, 1978, pp. 453-466. doi:10.1016/S0021-9673(00)85082-7

[43] T. R. Rybolt and C. E. Wells, "Molecule-Surface Binding Energies from Molecular Mechanics: Nucleobases on Graphene," In: H. E. Chan, Ed., Graphene and Graphite Materials, Nova Science Publishers, New York, 2009, pp. 95-112.

[44] C. Thierfelder, M. Witte, S. Blankenburg, E. Rauls and W. G. Schmidt, "Methane Adsorption on Graphene from First Principles Including Dispersion Interaction," Surface Science, Vol. 605, No. 7-8, 2011, pp. 746-749. doi:10.1016/j.susc.2011.01.012

[45] O. Engkvist, P. Astrand and G. Karlstrom, "Accurate Intermolecular Potentials Obtained from Molecular Wave Functions: Bridging the Gap between Quantum Chemis- try and Molecular Simulations," Chemical Reviews, Vol. 100, No. 11, 2000, pp. 4087-4108. doi:10.1021/cr9900477

[46] Y. Zhao and D. G. Truhlar, "Density Functionals for Noncovalent Interaction Energies of Biological Importance," Journal of Chemical Theory and Computation, Vol. 3, No. 1, 2007, pp. 289-300. doi:10.1021/ct6002719

[47] R. Zacharia, H. Ulbricht and T. Hertel, "Interlayer Cohesive Energy of Graphite from Thermal Desorption of Polyaromatic Hydrocarbons," Physical Review B, Vol. 69, No. 15, 2004, Article ID: 155406. doi:10.1103/PhysRevB.69.155406

[48] H. Ruuska and T. A. Pakkanen, “Ab Initio Study of Interlayer Interaction of Graphite: Benzene-Coronene and Coronene Dimer Two-layer Models," Journal of Physical Chemistry B, Vol. 105, No. 39, 2001, pp. 9541-9547. doi:10.1021/jp011512i

[49] T. P. Tauer and C. D. Sherrill, "Beyond the Benzene Dimer: An Investigation of the Additivity of $\pi-\pi$ Interactions," Journal of Physical Chemistry A, Vol. 109, No. 46, 2005, pp. 10475-10478. doi:10.1021/jp0553479 